\title{
Penal Measures and Policies Governing the Phenomenon of Human Trafficking with a Look at International Documents
}

\author{
Ahmad Purebrahim ${ }^{1} \&$ Iraj Go ldozian ${ }^{2,3}$ \\ ${ }^{1}$ Member of Young Researchers Club and Elite, University of Chalus, Iran \\ ${ }^{2}$ University of Paris, France \\ ${ }^{3}$ Faculty of Law and Political Sciences, University of Tehran, Iran
}

Received: June 27, 2016 Accepted: July 20, 201x Online Published: July 31, 2016

doi:10.5539/jpl.v9n6p68

URL: http://d x.doi.org/10.5539/jpl.v9n6p68

\begin{abstract}
Human dignity, and respect and commitment to it, is considered as one of fundamental principles of divine religions and international instruments on human rights. Benefit from valuable moral and theological virtues in order to provide of human growth and development exclusively is in the light of fundamental rights and the principle of preserving human dignity. Accordingly, today the concept of human rights and commitment to follow it in the international and national legal systems has a very important position. Rejection of all forms of exploitation humiliation and torture is one of the first underlying layer of hu man rights which known as negative human rights or social Don'ts. Although as the interpretation of the famous French philosopher Jean-Jacques Rousseau in the eighteenth century, human is born free but in the process of social life and adapting to social situations in different ways to be distracted from their pure nature. Countless people in the world today are subject to oppression, even are subject to varying degrees of slavery instances including humiliation and degradation and prostitution. This research attempts to analyze the irreparable consequences of this phenomenon on human society, and also to look beyond national and transnational criminal measures and policies on this phenomenon.
\end{abstract}

Keywords: human trafficking, modern slavery, prostitution, international conventions, organized crimes

\section{Introduction}

The phenomenon of human trafficking for prostitution and sexual exploitation is one of the forms of human trafficking at the international level and is a transnational organized crime. This phenomenon is a major problem and engaging in various countries' legal system, including our country's legal system.

After the victory of the Islamic Revolution and the formation of Isla mic Consultative Assembly, the drafters of the Islamic Penal Code, with regard to the principles of law and adherence to religious rules (Sharia Law), in order to preserve and protect the authentic values of Islamic morality in the provisions the Islamic Penal Code, have criminalized (according the case) the committing any acts incompatible with chastity and public ethics. These regulations will be implemented within the country, but outside the country (due to the implementation of Article 3 of the Civil Code of Iran), except in some cases, is not applicable.

On the one hand, the increase in the smuggling of Iranian women and girls abroad, and on the other hand the lack of a comprehensive and proper law about human trafficking, especially trafficking of wo men, finally a law on combating human trafficking was approved on 18.07.2004. The legislation would partly fill this gap, but left many ambiguities and failed to fully respond to problems such as trafficking in women and children for prostitution in tourist countries such as the Persian Gulf and some European and American countries. The international community has been concerned this is sue and documents and Additional Protocol I to international conventions such as the UN Convention against Transnational Organized Crime as to prevent, prohibit and punish trafficking in persons especially women and children as well as regional instruments such as the Convention on the East Asian Union, known as the Convention on SARS to prevent and combat trafficking in wo men and children for combat prostitution, is approved. 


\section{Chapter One: Take a Look at Protection Arrangements}

\subsection{First Topic: Protect the Private Identity of Victims}

Many victims of human trafficking, because the fear of their safety, or notorious scandals of them or their families and judicial proceedings against them or fear of dealing with the competent authorities avoid the indictment or complaint against traffickers, which usually associated with disclosure of their identity. So the security of victims in the process of identifying and working with the competent authority (either police or judges) are the most important tasks of governments, and one of the appropriate support measures is providing victims' security, identity and privacy of their private lives. Because disclose the identity, address and details of the private life of victims increases the risk of revenge on them and their families, or the risk of not oriety and dis grace for them in society or in the commun ity of origin and destination as well.

Therefore, in addition to some international documents such as the Declaration of Basic Principles of Justice for Victims of Crime and Abuse of Power, adopted by the UN General Assembly in 1985 (Clause D of paragraph 6), the Protocol to Prevent, Suppress and Punish Trafficking in Persons, especially Women and Children, attached to the United Nations Convention on Transnational Organized Crime Act 2000, known as the Palermo Protocol on human trafficking, in paragraph 1 of Article 6, with non-binding interpretations wants governments appropriately and in an extent possible way and in accordance with national law, avoid disclosure the identity of the victims and their personal life.

Among the measures that could have prevented the disclosure of the identity of the victims and to help providing their security, is appropriate legal acts, such as the confidential and non-public criminal proceedings and prevent the presence of the hearing (see clause 1 the 6 protocol), the legal impose some restrictions on the media (e.g., restrictions on media representatives to attend the hearing or limit the dissemination of information and details that reveal the identity of victims of crime).

The courts also should have the right, where appropriate, to declare the crime victims' identity confidential, or avoid the confrontation of the accused and witnesses. Obviously, some of these measures needs to reform criminal procedure of countries, particularly with pressure on governments by civil society groups will be realized. If the govern ment insists on the announcement the names of crime victims (especially those who testify against traffickers), civil society groups should force the government to provide appropriate new residence and new identity for victim (and in some cases for their families) as long as the risk remains, so that if the government refused to perform this task, victims do not cooperate with the competent authority.

\subsection{Second Topic: Global Health Supply for Victims}

The World Health and Integrity of human trafficking victims faces a variety of threats, violence and disease, especially victims who cooperate with the competent authority and give information to the authorities, which is effective in the pursuit of criminal groups and traffickers, are at risk of threats and intimidation or risk of reprisals, so that force them to silence and lack of cooperation. So, one of the tasks and responsibilities of state is providing the security and physical protection of victims, including against any abuses or retaliation of criminal groups, because as the threat or risk to the health of the victims of the crime is a new crime, in some cases damage to opportunity and speed of justice administration, or discourage other victims to contribute to justice and prevented from play ing a proper role of victims. Hence in some countries (like France) threaten the plaintiff for the extradition the complaint is considered as a crime (against justice). Palermo Convention on organized crime with realizing this fact in clauses in 24 and 25, provide the physical health of victims and witnesses. Consequently, Palermo Protocol with a weak and non-binding language in paragraph 5 of Article 6, only cited to governments efforts to provide security for victims, as long as they are not necessarily in their territory before reaching home (Eyni, 2011, p 28).

Some of the measures that provide the health of the victims have judicial nature and their implementation by correcting the provisions of criminal procedure and proving grounds is possible. These include:

- The trial behind closed doors and not hearing by the public: Because Public trial is not an absolute rule and, in some cases, to consider the public and moral interests, all or part of the proceedings will be closed.

- Registration and recording the statements (like writing or record ing).

- Testify anonymously or with pseudonym.

- Using audiovisual technology: rather than meeting face to face.

In recent years, some countries, particularly in relation to crime and sexual assault use this method, but this 
practice is not widespread in Europe, although in some countries, children are appeared in the court by video conference.

These measures should be implemented in such a way that a reasonable balance should be developed between the right to defense and the rights and interests of victims. That is why Article 30 of the Council of Europe Convention on Action against Hu man Trafficking, with a hu manitarian approach, stipulates that these protective efforts, namely the right to a fair trial, should be done according to Article 6 of The European Convention on Hu man Rights.

\subsection{Third Topic: Compensation}

In the process of cruel and inhumane crime of human trafficking, often victims suffered physical and psychological injuries or damage, and economic and commercial exploitation of them gave s mugglers a lot of illegitimate interests. Hence compensation and reparations to the victims, is a necessary step to overcome the imposed injuries, and helps victims in the light of justice, to imp rove their life.

Compensation claims can include global violence and psychological in juries, medical expenses, unpaid or very low wages, reimbursement expenses paid illegally by victims for employ ment agencies or for transportation, imposed fines to victims by traffickers for bad behaviors of victims, unlawful the excessive and fraudulent deductions from wages due to rent, the salaries, taxes, etc. According to the Declaration of Basic Principles of Justice for Victims of Crime and Abuse of Power, claims shall not be limited to these cases, and can also include significant damages to the environment. Also in accordance with paragraph 11 / A Declaration of Basic Principles of Justice for Victims of Crime and Abuse of Power, in cases where officials have violated national regulations contributed to the crime of human trafficking, victims can claim the govern ment for the damages. Compensation is not limited only to the victim, but includes the victim's family and relatives of the deceased or incapacitated and disabled victim due to physically and psychologically injuries. (Paragraph $12 \mathrm{~B} /$ mentioned Declaration).

In paragraph 6 of Artic le 6 of the Palermo Protocol, without referring explicitly to the right of the victim to claim damages from the perpetrators of the crime of human trafficking, with a poor language, provides the possibility of receiving compensation as follows: "Each Contracting State will ensure that its national law, adopt measures that the victims of human trafficking, can receive compensation for the limitation of victims from the funds of the government which provided compensation for victims."

The Convention on Transnational Organized Crime, with more strong language, in paragraph 2 of Article 25, stipulates the right for Compensating to file a lawsuit against the property of traffickers (Zaghli, 2010, p 214).

\section{Chapter 2: Penal Policy}

\subsection{First Topic: Legislative Actions}

Legislative actions mean the measures taken by the legislator against smuggling. These reactions included a range of penalties from cash fine to the death penalty. Because the legislator's response to the initial effects of human trafficking, such as adultery and panderism, which is based on the religious texts, varies from lashes to the death penalty. On the other hand, non-Hudud punishments intended for some of these cases is often imprisonment or a cash fine. For example, under Article 211 and 213 of the former General Penal Code, a person who makes a living from prostitution wo man help her in prostitution or encourage people to co mmit immorality and lust and Panderism, operating a brothel and ease of women travel abroad for prostitution, were entitled to imprisonment and cash fine.

One of the remarkable notes on Article 213 is wo men trafficking for committing prostitution outside the country. Also the differential protection of children and attention to the position of predicator made in paragraph 4 of Article 211 of are the strengths of this Act. Because according to this paragraph, forcing people less than 18 years to corruption, prostitution and the act of a parent or guardian or one of the other persons, mentioned in the last paragraph of Article 207 of the same Act, causes exacerbated the punishment of perpetrators. On this basis, under the influence of international instruments and obligations arising fro $m$ those documents, the exploitation of others' prostitution is legally a crime and provides criminal penalties. At the time, committing indecent acts (Article 210 Penal Code) and illegal association (Article 212 and paragraph b of Article 207 of Penal Code) was also criminalized.

Also pursuant to Article 5 of the Security and Corrective Measures, willing to commit prostitution or earn a living through this criminal turns to habits and leading to keep offender in exile for an undetermined period. In addition, the court could compel the offender, who makes earn a living by prostitution, to keep in agriculture or industry give a workshop for an indefinite period, instead of imprisonment. 
In addition to these cases, the criminal policy of Iran is considered some non-criminal responses to the phenomenon of prostitution that can be seen in miscellaneous laws.

For example, a ban on the public screening of any film in theaters and cinemas and supply or sell them on the market, if they involves the spread of vice actions and corruption and prostitution, the investigation to the properties of those who were organized the places of prostitution and corruption and the necessity of lack of reputation for moral corruption and promiscuity (prostitution and rape) for entrance to university can be cited.

Dispersion laws related to combat with the various manifestations of human exploitation in the law of Iran prevented the adoption of a consistent and efficient criminal policy in this regard.

Dispersed responses in this area caused inconsistency in the considered responses to these cases. But it can be obtained from all of these reactions that the legislator in most such cases exhibits a sweeping authoritarian criminal policy pattern, focusing on violent and repressive reactions especially by government (Hosseini, 2004, $p$ 122)

\subsection{The Second Topic: The Awareness Measures about the Dangers of Human Trafficking}

The United Nations, along with the adoption of international documents and regulations in the field of human trafficking and its related crimes (including slavery, sexual exploitation, etc.) in order to accelerate the implementation of the relevant documents and awareness of different nations and states, attempt to hold conferences and meetings at international level and sometimes in a specific region of the world. This organization by holding these conferences, gathers the necessary information about the attention of the international community in the context of the Conventions and other binding and guidance documents, and also examines the strengths and weaknesses of these documents.

The United Nations in line with its criminal approach and policy of preventing all forms of violence against wo men and raise awareness of the government's, attempts to establish Several conferences, including conferen ce of Mexico City in 1975, the Copenhagen conference in 1980, The Nairobi conference in 1985 and the Beijing Conference in 1995.

The vulnerability of children to violence, sexual and physical exp loitation, trafficking and other organized crimes, has led the international institutions that along to their efforts to pass guidance and binding documents for preventing and suppressing these crimes, organize numerous conferences for their organizational goals and awareness of governments as well as evaluating the measured taken, after the adoption of the aforementioned documents. The first United Nations World Conference on Children's Rights with the participation of heads of seventy-one countries held in New York. At this meeting, different aspects of children's issues were examined. In this conference, the vulnerability of children by their environ ment and child victims of violence and exploitation were also mentioned.

The outcome of this meeting was the adoption of the Universal Declaration of survival, development and protection of children and the Action Plan for the implementation of the Universal Declaration in 1990. Under the Declaration which adopted on 25 Article, heads of state accepted some obligations about the guarantee of the rights of children in nu merous fields.

The second International Conference on Population and Develop ment took place in 1994 and set to improve the demographic and population growth. The theme of the conference was mainly study of population growth, health and family (Abbaschi, 2001, p 86).

\section{Third Chapter: Human Trafficking in the Light of Some International Documents}

\subsection{First Topic: The Palermo Convention and Its Additional Protocol II}

Although the international community paid attention to this issue very late, but the development procedure in this field was done fairly quickly and the International Convention in Palermo was signed by governments in last days of 1990 and the second millenniu m (Salimi, 2003, 9/1)

However, the latest international convention which has been discussed ever about combating human trafficking is the Second Additional Protocol to the Palermo Convention entitled "Prevent, suppress and punish of Human Traffickers, especially wo men and children traffickers" that approved on November 2000, in Palermo Italy.

But what is necessary to note about the purpose of this Protocol is that, the purpose of this Protocol is combating against all forms of Human Trafficking, both male and female. Of Course, because the greater vulnerability of wo men and children in this regard, special emphasis has been laid on it. Meanwhile the purpose of this Protocol, unlike some of the previous documents is merely to prevent the trafficking of women and enact measures to prevent the occurrence of this crime. Also it wants governments to play more active role in cracking down this 
crime, and imposes Contracting States to make wo men trafficking as criminal implications in their national law.

In fact this protocol is seriously aimed at punishing trafficker, the protection of victims of human trafficking. Prevention, cooperation and other measures are other goals of this protocol (Mirmohammad Sadeghi, 1998, p 316)

\subsection{The Second Topic: The International Convention May 18, 1904, Concerning the Provision of an Effective Protection against Criminal Transactions, Known as the Buying and Selling Whites}

A review of international documents on human rights indicates the fact that the history of the development of international instruments for the protection of women's rights approval, dating back to les s than a century.

Also overview of wo men's rights international instruments sugges ts that the main concern of the elite community of nations in the first decade of the twentieth century is the problem of purchase and sale of white women and hired them for prostitution and the need to deal with this social phenomenon rather than the equal rights with men. But after a few decades of global thinking it approached towards the evolution of women problems and their rights. After the victory of United States of A merica in the Civil War that took place aiming at the abolition of slavery, the slave trade and slavery throughout the world apparently went into a decline, but a more tragic form of modern slavery, which included the exploitation of human labor, especially the abuse of women and children and also hired them to sexual abuse became extremely common. Therefore, the first international document on the rights of women on May 18, 1904 in Paris entitled "International Convention on providing an effective protection against criminal transaction, known as the buying and selling of whites" to deal with the sexual abuse of women and girls and hired them for prostitution was signed, and the Contracting States, by acceding to the Convention, shall committed (in addition to deal with those who are attempting to hire women and girls for prostitution) to return the girls and women which have been sent to other countries for prostitution to their homeland. The above Protocol has been considered due to efforts to protect the rights of wo men. The ultimate purpose of this Convention is the commitment of member states to adopt measures to prevent the transmission of women and girls abroad for debauchery and prostitution (Ebadi, 1993, p 32). It should be noted that, this Protocol didn't provide any definition for Women trafficking or buying and selling of wo men and girls and perhaps at that time there was a consensus on definition of them. In this context, it is emphasized on obligations of States to prevent and taking measures to prevent the buying and selling of women (Hedayati, 1966, p 24), and Convention member States shall take appropriate measures to protect women and girls for transmission to abroad for the debauchery, especially in matters related to railways and tourism ports and travel. So in this regard, the necessary training should be done for agents to identify the ways to deal with discovering criminal cases. Articles 3 and 5 this Convention is dedicated to the issue of returning trafficked wo men to their homeland. Of course, they must return trafficked wo men willingly and can not force trafficked wo men to go out of the country of destination. Preventive provisions in Article 6 will also be introduced in such a way which the trafficking and buying and selling of wo men will not occur. But criminal consideration of this is sue is not raised in it, thus this legal gap led to not deal with this crime. But, as a rule, either it should considered as an independent offense and punishable on all States Parties to the Convention, or otherwise Contracting States should determine it as a crime in their own domestic laws. So, despite this legal gap, no special enforcement in order to combat this crime had been determined and the perpetrators of this criminal act more easily and thus the government's efforts to prevent the crime looks barren.

\subsection{The Third Topic: International Convention for the Suppression of the White Slave Traffic on 4 May 1910}

In order to solve the above-mentioned contradiction, another International Agreement entitled "International Convention for the Suppression of the White Slave Traffic" was signed in Paris on May 4, 1910, which in fact was a complementary for the in itial treaty in 1904. In Article 1 of this treaty "Whoever, in order to gratify the passions of another person, has procured, enticed, or led away, even with her consent, a wo man or girl under age, for immoral purposes, shall be punished, notwithstanding that the various acts constituting the offence may have been committed in different countries" (Ibid, 20). It is worth to mention in this Agreement that any sexual exploitation in every possible way is an act against human rights, and the consent of the wo man as an object, has no effect in changing inhuman nature of this action.

The notable point in relation to the above-mentioned convention is that it is considered solely the trafficking of wo men as a crime for the purpose of sexual exploitation and trafficking in wo men that may take place with other purposes of exploitation still has legislation defect. For example, if the trafficking of women to be taken place for the purpose of a forced marriage or hardworking, it is out of the scope of this Agreement specially. It is worth to mention that with the beginning of World War I, most of the signatories of the above-mentioned documents became enemies of each other and consequently the implementation of the content of the present documents 
virtually suspended.

\section{Conclusion and Suggestions}

Many analysts believe that what is proposed today as the crime of human trafficking, which has very frightening dimensions in today's world has relationship with the slavery issues that was annulled after centuries in the late nineteenth and early twentieth eventually, however, some aspects and same procedures of it still $\mathrm{h}$ as remained somehow. The huge quantities of wo men trafficking were intensified like a wave from the early 1990s, for some analysts there was similarity with slavery and slave trade, hence it can be called human trafficking as "modern slavery" or "modern form of slaver,". Human trafficking is a very complicated issue which organized criminal groups are increasingly involved in it. In addition, the exploitation of man is not limited to sexual exploitation by no means, but also it includes several dimensions, which are included forced labor, forced marriage, household hard tasks and other exploitative practices. Indeed, still the trafficking of women for the purpose of prostitution or other forms of sexual exploitation constitutes the most important purpose of trafficking. One of the most common type of human trafficking that because of its huge benefits is the scope of organized groups and gangs, is the trafficking in women and girls for using in the places of corruption and prostitution and forcing them into prostitution, sometimes using them as a service. Now, trading girls and young women by human trafficking gangs from around the world to Europe and other regions of the world has found a wider dimension. Human traffickers deceive job seeker wo men and girls with the promises of good jobs and incomes, hide them as slaves and prisoners of past centuries in the warehouses of ships, and arrive European countries or other countries with the deplorable ways. But many of these illegal immigrants fall into the hands of mafia and come out of corruption centers. An increase in trafficking in women and girls just because of huge profits that gives the traffickers has become a global catastrophe. Governments have not yet achieved success in preventing trafficking in women by all efforts and implementing projects to fight against this phenomenon. The Islamic Republic of Iran also has sensed the danger of this transnational crime very well and has done measures in this field, including the adoption of the law of combating hu man trafficking in July 2004. The adoption of the law of combat human trafficking by the Parliament on July 19, 2004 is a big step that greatly covers the gaps, given that in the domestic laws before the enactment of this Act, any specific law that becomes highly relevant to the criminal topic was not approved. Furthermore, according to the definition provided in this Law of Human Trafficking, which is remarkably similar to the definition set out in Convention 2000, in fact, the legal framework for the definition of the crime has given largely to the discretion of the adjudicating authorities, which it is considered as a major obstacle in the direction of the violation of the rights, the freedoms of people and the freedom of travel. Perhaps one of the main drawbacks of the law can be related to the protection of victims and prevention of crime occurrence. Victims supporting in this Act has been somewhat overlooked and it was not stipulated in the legal provisions that this also raises doubts to some extent, which the victim of trafficking in persons, not only are as victims but also to some extent be regarded as criminal, which the concern about the victims will cause that the victims of the crime avoid discussing the matter with the concerned authorities. On the other hand, it has let that not only the prevention of crime was not realized, but also the way to identify criminal gangs through the guidance of victims is completely blocked.

According to the results that were cited, the following points are proposed:

- Legislator using documents and international conventions provide a detailed definition of crime of human trafficking; especially the purposes and goals set forth in the Law on Combating Trafficking in Persons are limitative.

- Legislator determine ru les to the entered material and spiritual damages to the victim of human trafficking explicitly, and as the necessity of compensation of it has been stipulated in the laws like the law of civil liability, the sentence of the compensation of such damages in human trafficking be considered legal. The second paragraph of Article 9 of the Code of Criminal Procedure be reinstated as the primary, which has been removed in the procedure code of public and revolutionary courts in criminal matters, it be mentioned expressly in the law of the fight against trafficking.

- According to circumstance, in collaboration with NGOs and grassroots organizations, provide the following case for victims of hu man trafficking:

Providing affordable housing, advising and giving the necessary information, especially about their legal rights, medical, psychological and material assistances, creating job and educational opportunities for victims of crime.

- It is recommended that the actions and measures to be taken to prevent trafficking in persons by the government, including: 
(A) Adopting measures such as research and giving information and media advertising, social, and economic initiatives.

(B) Reducing and minimizing factors that make persons defenselessness, especially wo men and chi ldren against trafficking, such as poverty, underdevelopment and lack of equal opportunities.

(C) The strengthening of border controls at entrances and exits and during the trip.

\section{References}

Abachy, M. (1380). Juvenile criminal law in documents of the United Nations (1st ed.). Tehran, Majd Publications.

Ashtary, B. (1380). Women trafficking, contemporary slavery. "Andisheh Bartar" publications.

Ebadi, S. (1372). History and Documentation of Human Rights in Iran. Tehran, Roshangaran publications.

Eyni, M. (n.d.). Providing security, compensation and repatriation of victims of trafficking in international documents, the doctrine of criminal law journals, research, spring 90, No. 19.

Glan, G. V. (1379). The inter-governments rights, Introduction to Public International Law (Vol. II). translated by Mohammad Hossein Hafezian. Tehran, Mizan publications.

Has aninezhad, H. (1373). International criminal law. Tehran, Mizan publications.

International Convention signed in Paris on May 18, 1904, quoted from: Hedayati, Mohammad Ali, A set of mu ltilateral international agree ments Iran, 1345, Tehran: Taban publications.

Laws and regulations relating to wo men in Iran, Tehran, Presidential Office for Women's Affairs, 1372.

Mir Mohammad Sadeghi, H. (1377). The international criminal law (1st ed.).

Ramazan Nargesi, R. (n.d.). Wo men Trafficking in the absence of dos and don'ts, "Cultural and Social Council of Women" Quarterly, $19^{\text {th }}$ edition, Spring 82.

The Holy Quran.

United Nations. (1995). from Nairobi to Beijing. New York: optic, p. 126.

United Nations. (2001). Beijing Declaration and plat Form Action, with the Beijing+5, political Declaration and outcome. New York. p. 155.

Zaghli, A. (1389, Autumn). Human Trafficking in Iran criminal policy and international documents (1st ed.). Mizan publications.

\section{Copyrights}

Copyright for this article is retained by the author(s), with first publication rights granted to the journal.

This is an open-access article distributed under the terms and conditions of the Creative Commons Attribution license (http://creativecommons.org/licenses/by/4.0/). 